\title{
Assessing battery energy storage for integration with hybrid propulsion and high energy weapons
}

\author{
L Farrier* MEng MSc AMIMarEST, R Bucknall* MIET, MSNAME, MIMarEST \\ * University College London, Department of Mechanical Engineering, London, UK \\ * Corresponding Author Email: luke.farrier.14@ucl.ac.uk
}

\begin{abstract}
Synopsis
In the future warship power and propulsion systems need to be designed for increased flexibility, in part to sustain the demand of changing load profiles such as those characterised by high ramp-rates of new weapons and sensors intended to support enhanced future warfighting capability. Lithium-ion based battery performance is improving at a prominent pace in the automotive sector, increasing in both energy and power density, thus there is now an opportunity to exploit these characteristics for naval power systems. A common use energy storage system could facilitate benefits such as reduced fuel burn and prime mover running hours by reducing the number of running generator sets. Importantly, the improvement in battery systems, has reached a juncture where the technology could be considered to support directed energy weapons. The feasibility of a Lithiumion NMC based energy storage system, capable of high discharge rates, to power predicted laser directed energy weapons using time domain simulation is investigated in this paper. Results verify that the simulated system is capable of high rates of fire for extended periods subject to state of charge operating limitations.
\end{abstract}

Keywords: Battery energy storage, high-energy lasers, hybrid propulsion.

\section{Introduction}

Recent technological developments in electrochemical energy storage devices in parallel sectors have transferable benefits to naval ship power system design. Practical specific energy and power density of Lithiumion (Li-ion) batteries are attaining $150-250 \mathrm{Wh} / \mathrm{kg}$ and $200-450 \mathrm{~W} / \mathrm{L}$ respectively for battery cells used in electric vehicle applications (Benveniste et al. 2018). Developments such as Lithium Sulphur chemistries demonstrate that battery cells could exhibit specific energy density upwards of $500 \mathrm{Wh} / \mathrm{kg}$ and $900 \mathrm{~W} / \mathrm{L}$ (Nagata and Chikusa 2016). These attributes introduce the prospect of increasingly compact battery systems that can improve ship power system performance during low threat operations and compensate anticipated highly dynamic combat system loads. This is particularly attractive for warships with hybrid propulsion that have the aspiration to integrate future pulsed power loads such as laser directed energy weapons (LDEWs), where power generation capability is intrinsically reduced compared to full electric platforms.

Battery based pulsed power is not in itself a novel concept, Huhman et al. (2016) describe the design of a battery system used to charge a capacitive device capable of delivering $12 \mathrm{~kJ} / \mathrm{s}$ at 10 cycles per minute for a 5 minute, 50 shot salvo. Gattozzi et al. (2015) investigated the ability of a Li-ion Energy Storage System (ESS) to power sub $125 \mathrm{~kW}$ LDEW loads, however little discussion was offered on the Li-ion battery model fidelity. This investigation differs for two reasons, firstly the battery system is the sole source for the pulsed load as opposed to a battery/capacitor combination for electromagnetic launch purposes as researched by Huhman et al. (2016). Secondly, the investigated LDEW loads are significantly greater, being $1.5,1.75$ and $2 \mathrm{MW}$, and could be required to power the pulsed load for a period of at least four minutes (Markle 2018).

In this work a 'common-use' battery ESS is explored to power these anticipated LDEW loads. These loads are exerted on an ESS that utilises Li-ion Nickel Manganese Cobalt (NMC) chemistry. NMC is currently used in electric vehicle and commercial shipping battery system applications due to a balance of high specific energy and power as a consequence of high cell voltage (typically 4.1-4.3 V per cell) and low internal resistance, moreover NMC has a relatively high thermal runway temperature (Chemali et al. 2016). The battery ESS could benefit the power system by mitigating the reported adverse effects exhibited on QPS and power generation components from pulsating loads (Langston et al. 2017, Mills et al. 2018). This paper aims to firstly, justify the integration location of the ESS and pulsed load within a candidate power system. Secondly, to investigate the system response, and finally to define the operating envelope of the NMC based battery system under the LDEW pulse load parameters defined in Section 2.

\section{Author Biographies}

Luke Farrier is a Marine Engineering Research Assistant at UCL and $3^{\text {rd }}$ year PhD student investigating power system performance when integrating energy storage systems. Prior to this he obtained a degree in Mechanical Engineering from the University of Exeter, after which he completed the graduate scheme with MoD Defence Equipment and Support where he obtained his MSc in Marine Engineering from UCL. Prof. Richard Bucknall is the Professor of Marine and Power Systems Engineering and the Department's Director of Research. His areas of interest include low carbon shipping, hybrid and fuel cell propulsion, autonomous vehicles. His collaborative projects have included industry partners such as UK MoD, Rolls Royce and BMT and he works internationally with organisations in EU, China and USA. 


\section{Case study}

Consider the power and propulsion system shown in Figure 1. The reference system is combined diesel electric or gas turbine (CODLOG), the details leveraged from Gemmell et al. (2014) and McNaughtan et al. (2016). Review of the system schematic highlights two options for the integration location of the battery that permit both operation of the pulse load and improving wider power system performance during the wider operating profile. Firstly, with the main switchboard via DC/AC converter interface or secondly, with the DC link of the propulsion converter via a DC/DC converter. In the second option controlling the charge/discharge of the battery whilst maintaining a stable DC link voltage is challenging (Radan et al. 2016), this is exacerbated when a current pulse with high di/dt induces battery voltage drop due to low internal resistance, such as an LDEW load. The extent of this voltage drop is demonstrated later in Section 4. Thus, to decouple the fight and move capability the battery ESS was integrated with the main switchboards as shown in Figure 2 for a half ship set.

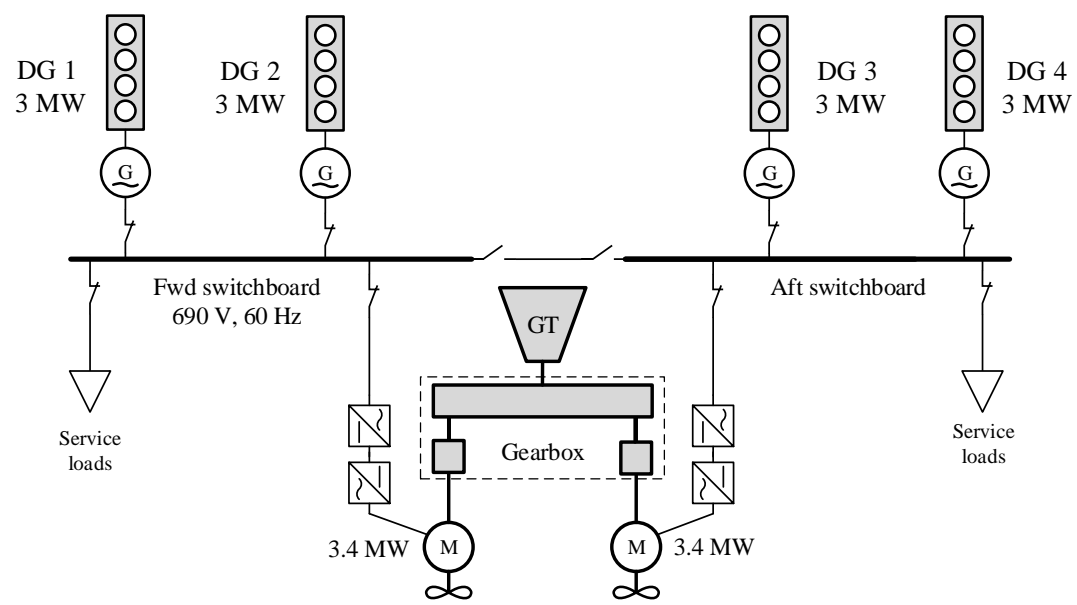

Figure 1: Reference system architecture for case study

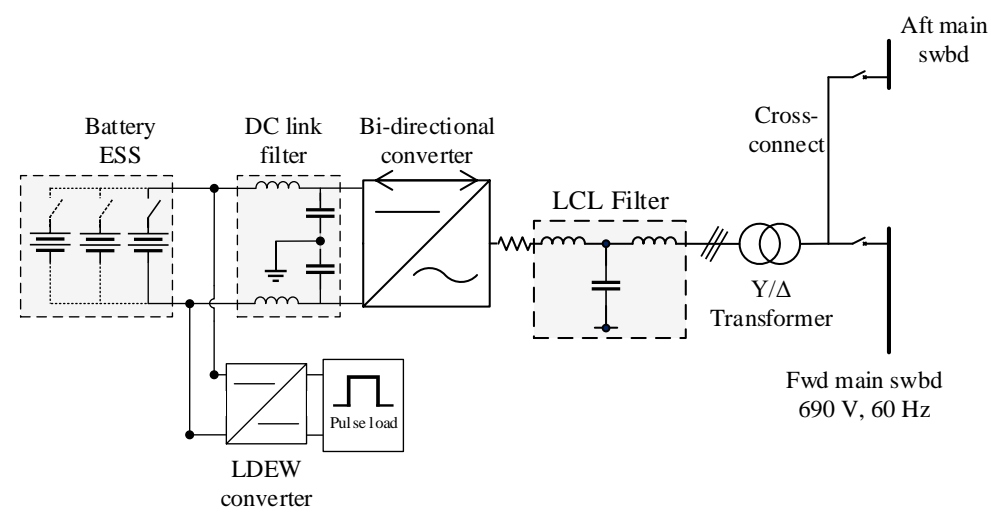

Figure 2: ESS and LDEW integration schematic for half ship set

The battery ESS in Figure 2 is integrated with the main distribution system via a PWM bridge, passive components and input transformer. The passive components constitute a DC and AC side filter, associated with power quality (drawn from the battery and supplied to the ship) and the AC side filter is further influential in the control of the converter. The wye-delta transformer is a robust method of providing galvanic isolation from the bidirectional converter to the distribution system due to the delta connection (Wakileh 2001). The LDEW is connected to the ESS DC-link via a DC/DC boost converter. This arrangement permits ESS and LDEW to be decoupled from the main switchboard during operation. Therefore, this avoids adverse QPS conditions on the main switchboard resulting from the pulsating load. Moreover, avoiding the higher losses associated with discharging from the ESS to an LDEW via the main switchboard as demonstrated by Figure 3, this is between 7-10\% loss at higher current rates depending on SoC. 
(a)

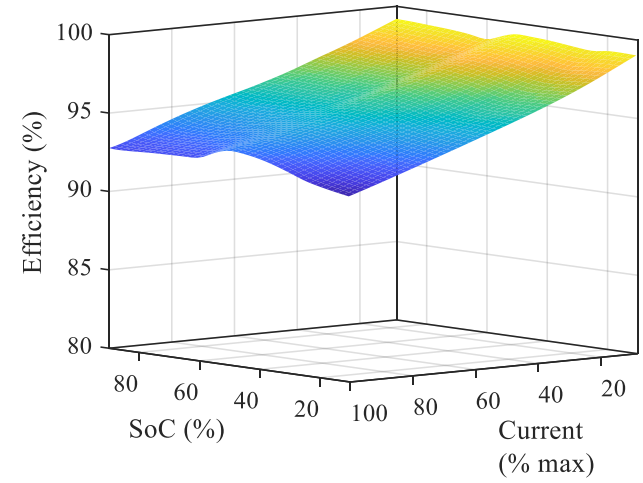

(b)

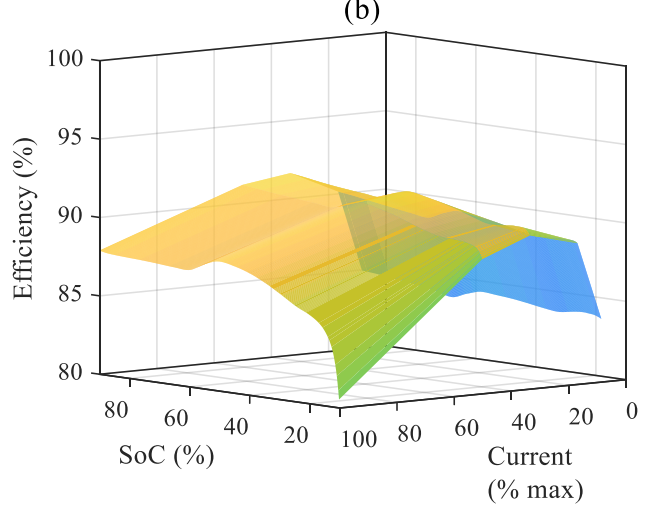

Figure 3: Analytical thermal efficiency map over battery discharge measured at (a) battery terminals i.e. connection to the LDEW converter and (b) connection to the main switchboard

The LDEW parameters of interest in this work are derived from Mills et al. (2018), presented in Table 1. The load demand is the total input power to the weapon, which takes the LDEW inefficiency into account, assumed here as $75 \%$ (O’Rourke 2015).

Table 1: LDEW load parameters of interest

\begin{tabular}{ll}
\hline Parameter & Value \\
\hline Pulsed load demand & $2,1.75,1.5 \mathrm{MW}$ \\
Pulse duration & $2.5 \mathrm{~s}$ \\
Duty cycle & $40 \%$ \\
DC base load & $50 \mathrm{~kW}$ \\
\hline
\end{tabular}

Assuming 97\% DC-DC converter efficiency (Kazimierczuk 2016), the maximum steady state power limits of the ESS under investigation are shown in Figure 4, reflecting the Orca system from Corvus Energy rated at 500 $\mathrm{kWh}$. The volume and mass of each string is $1.36 \mathrm{~m}^{3}$ and $1,550 \mathrm{~kg}$ respectively, this excludes the DC link filter and power electronic conversion equipment shown in Figure 2. This plot initially indicates to the system designer that a minimum of three strings are required in order to provide the LDEW loads using the particular NMC basedbattery ESS in this work, however not over the entire 20-90\% SoC operating range of the battery. Five strings would provide benefit in the number of LDEW shots available and higher power capability, however this raises the issue of DC fault protection on the common bus. The peak fault current contribution of each string is circa 12 kA (Southall and Ganti 2018). Therefore, four strings were used in this investigation.

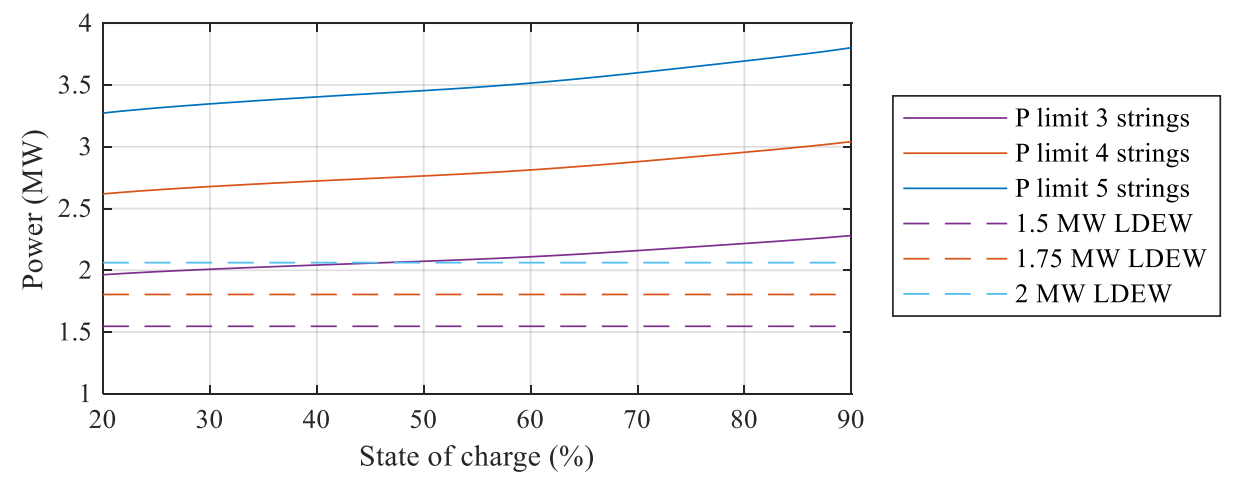

Figure 4: ESS string power limits and LDEW loads of interest- remove LDEW signs

\section{Simulation model}

The simulated circuit used to investigate the ability of the battery ESS to facilitate LDEW operation is presented in Figure 5. The respective components are described in the subsequent sections. The key system parameters are provided in Table 2 . 


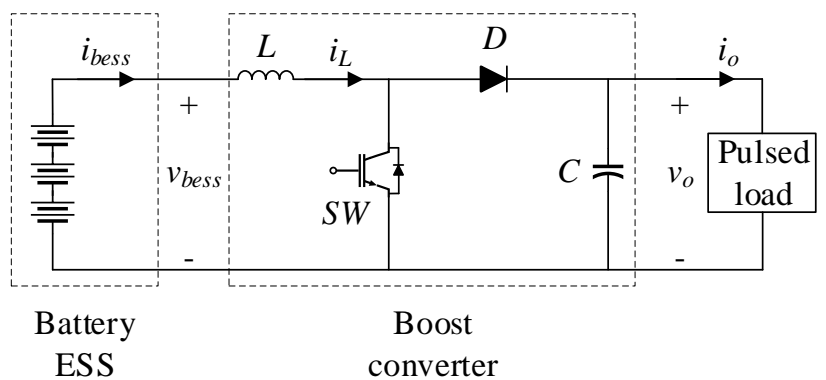

Figure 5: Simulated circuit

Table 2: System modelling parameters

\begin{tabular}{ll|ll}
\hline Parameter & Value & Parameter & Value \\
\hline Peak battery voltage & $1100 \mathrm{~V}$ & Input inductor, $L$ & $900 \mu \mathrm{H}$ \\
Nominal voltage & $980 \mathrm{~V}$ & Output voltage, $v_{o}$ & $1400 \mathrm{~V}$ \\
Cutoff voltage & $800 \mathrm{~V}$ & Output capacitor, $C$ & $10 \mathrm{mF}$ \\
Modules per string & 22 & PWM switching frequency & $4000 \mathrm{~Hz}$ \\
\hline
\end{tabular}

\subsection{Battery ESS}

A second order behavioural Thévenin equivalent circuit model is demonstrative of a Li-ion NMC pouch cell, rated between 60-70 $\mathrm{Ah}$. The cell model is scaled in series and parallel to represent the battery string described in Table 2. The cell circuit model in Figure 6 includes open circuit voltage $u_{o c}$, equivalent series resistance $R_{0}$, transient circuit voltages, $u_{1}$, and $u_{2}$, with associated non-linear complex impedance represented by resistorcapacitor pairs. These parameters do not represent the battery internal components. Instead, these parameters denote a state-variable representation of the battery from the perspective of the cell terminals. These parameters are mapped using high order polynomial functions dependent on SoC. The SoC is estimated using coulomb counting, determined using (1), where $\mathrm{Q}$ is the battery capacity and $i_{b}$ is the battery terminal current. There are many other methods in the literature such as a Kalman filter techniques that can be highly accurate (Hannan et al. 2017), however coulomb counting is a robust method highly suitable for simulation purposes (Kalikatzarakis et al. 2018).

$$
s_{Q}=s_{Q 0}-\frac{1}{Q} \int i_{b} d t
$$

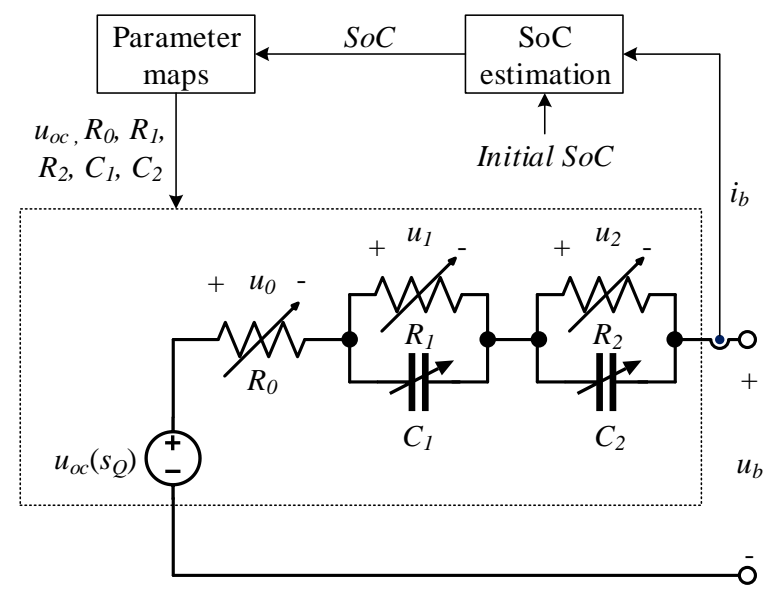

Figure 6: Lithium-ion battery Thévenin equivalent circuit 
The order of the circuit model defines the precision of the voltage response under charge and discharge conditions. A second order circuit with two RC pairs provides a good balance between accuracy, complexity and computational expense (Chen and Mora 2006). A first order model lacks resolution in the dynamic voltage response at system level, and is therefore more suitable for quasi-steady-state simulation (Hentunen et al. 2014). The first time constant of the circuit denotes the fast response of the battery dynamics, the second time constant is representative of the slower dynamics in the cell. The cell parameters for the model in this work were extracted from an experimental pulsed discharge (PD) test conducted at $0.5 \mathrm{C}$ rate at $5 \%$ pulse rate from $100 \%$ to $0 \%$ SoC with 30 minute rest period between pulses using the method described by Hentunen et al. (2014).

The model validation test series is provided in Table 3 for PD, constant current (CC) charging and constant current constant voltage charging (CCCV) results. The validation procedure correlates the voltage error when the model was subjected to current input data from the experimental tests. The error results increased substantially below $10 \%$ SoC, however the battery SoC range is limited during operation to $20-90 \%$ SoC to protect the cells (Hannan et al. 2017), thus this is deemed acceptable. The largest error pertains to 6C discharge, this is a consequence of the model parameterisation procedure at $0.5 \mathrm{C}$ and higher cell temperatures at higher current rates. To reduce the error, PD tests over the entire cell operating range at selected intervals would be required to generate more parameter maps, as demonstrated by Hentunen et al. (2014), however this is outside the scope of this work.

Table 3: Battery cell model validation results, SoC Range $20-90 \%$

\begin{tabular}{lll|l}
\hline \multirow{2}{*}{ Experiment } & \multicolumn{2}{l|}{ Absolute error (\%) } & \% Error \\
\cline { 2 - 4 } & Max & Mean & RMS \\
\hline PD 0.5 C, 5\% pulse rate & $0.45 \%$ & $0.11 \%$ & $0.13 \%$ \\
CC discharge 0.5C & $0.81 \%$ & $0.55 \%$ & $0.57 \%$ \\
CC discharge 1C & $1.39 \%$ & $1.11 \%$ & $1.15 \%$ \\
CC discharge 2C & $2.81 \%$ & $2.14 \%$ & $2.23 \%$ \\
CC discharge 3C & $4.44 \%$ & $3.11 \%$ & $3.24 \%$ \\
CC discharge 6C & $8.68 \%$ & $5.70 \%$ & $5.90 \%$ \\
CCCV 0.5C & $0.67 \%$ & $0.37 \%$ & $0.41 \%$ \\
CCCV 1C & $1.26 \%$ & $0.72 \%$ & $0.85 \%$ \\
CCCV 2C & $2.76 \%$ & $1.72 \%$ & $1.90 \%$ \\
CCCV 3C & $4.19 \%$ & $2.64 \%$ & $2.90 \%$ \\
\hline
\end{tabular}

\subsection{Pulsed load}

The pulse load is modelled as a variable resistor with trapezoidal shape as described by Figure 7, the rise and fall time was assumed as $10 \mathrm{~ms}$. The control system was designed to enable faster rise times subject to the input inductor $\mathrm{di} / \mathrm{dt}$ limit of $0.94 \mathrm{kA} / \mathrm{ms}$ (at cutoff voltage). Lower inductance could increase rise time, but at the cost of higher current ripple, this increases the risk of EMI in the system. The input inductor and output capacitor ratings were designed to achieve $4 \%$ and $1 \%$ ripple for current and voltage respectively at $2 \mathrm{MW}$ pulsed load.

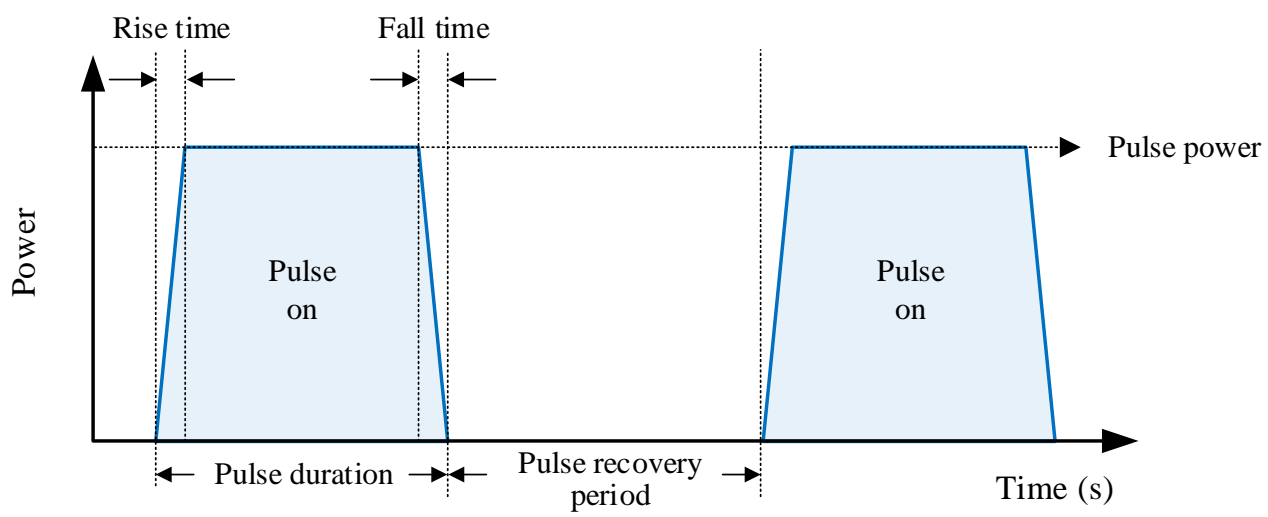

Figure 7: Trapezoidal pulse load profile 


\section{3. $\quad D C / D C$ converter and controller}

The DC/DC converter control system comprises an outer and inner loop PI controller in a cascaded configuration as presented in Figure 8. The outer loop regulates the output voltage $v_{O}$ and sets the command for the inner loop controller that is responsible for controlling the input inductor current $i_{L}$ subject to the maximum battery current $i_{\text {bmax }}$. The output of the inner loop controller is the duty cycle $d$, which governs the PWM switching signals that drive the IGBT switching devices. PI controllers are required to enable the fast response commanded by the pulsed load, a PID controller was not adopted as it would dampen the response due to its derivative term. A cascaded PI controller is appropriate to ensure the dynamic response of output voltage and current simultaneously (Özdemir and Erdem 2018). The feedforward controller mitigates the outer loop right hand plane zero, whose position fluctuates with load and battery voltage. Therefore, mitigating the control system instability under large load disturbances like the LDEW load investigated here.

To manage the high current associated with the system, the IGBT and diode characteristics used in the boost converter are based on the ABB 5SNA and 5SLA modules respectively (ABB 2014, 2015). The DC collector current ratings of $3600 \mathrm{~A}$ and device di/dt limits of $11.5 \mathrm{kA} / \mathrm{s}$ are compatible with the pulse characteristics.

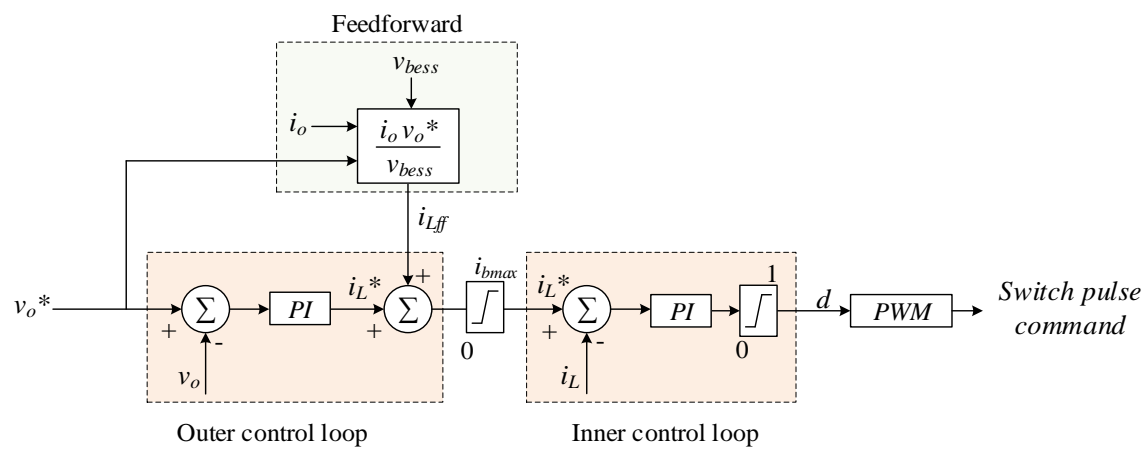

Figure 8: DC/DC converter controller

Table 4: DC/DC converter control parameters

\begin{tabular}{ll}
\hline Control parameter & Value \\
\hline Battery discharge current, $i_{b \max }$ & $6 \mathrm{C}$ \\
Inner loop proportional gain, $K_{p}$ & 0.002 \\
Inner loop integral gain, $K_{i}$ & 0.134 \\
Outer loop proportional gain, $K_{p 2}$ & 0.16 \\
Outer loop integral gain, $K_{i 2}$ & 75.3 \\
\hline
\end{tabular}

\subsection{Constraints and assumptions}

The following constraints were applied during this investigation:

- The battery ESS is assumed to be at a maximum of $90 \%$ and minimum of $50 \%$ SoC at commencement of LDEW operation. The maximum engagement time was set to 8 minutes.

- The simulated system described by Figure 5 is isolated from the main distribution system during LDEW operation.

- The simulation will terminate if either the $800 \mathrm{~V}$ cut-off voltage, $80 \%$ DoD or $6 \mathrm{C}$ current limit are exceeded. The model voltage validation error is taken into account for high discharge rates.

- The cells in the battery ESS are balanced and discharge equally, consequently all results are from the perspective of the battery ESS terminals.

- Thermal stress and cyclic aging effects are outside of the scope of this model. The potential effects from repetitive operation of parallel cells at elevated discharge rates are discussed further in Huhman et al. (2016) and Wetz et al. (2015). 


\section{Results and discussion}

The circuit described by Figure 5 was simulated in the MATLAB/Simulink R2018a modelling environment. The circuit was simulated for the load parameters in Table 2, conducted at $10 \%$ SoC intervals from $90-50 \%$ SoC this allows the operator to understand the maximum shots available for a given LDEW load.

\subsection{System response}

Figure 9 demonstrates the voltage and current response to the pulsating load, the engagement commenced at $5 \mathrm{~s}$ and successfully completes 9 shots. Consequently, verifying that the ESS and control system can provide a series of LDEW pulses. The simulation terminated when the voltage exceeded the cut-off voltage limit during the initial voltage drop of the $10^{\text {th }}$ shot, thus it is not shown here. Observation of $v_{o}$ in Figure 9(a) shows slight perturbations maintained at $1400 \mathrm{~V} \pm 50 \mathrm{~V}$, which is within the $10 \%$ recommended tolerance limits for DC power systems (IEEE Industry Applications Society 2018). When the LDEW is on, the battery voltage drop due to internal resistance in the cells varies from $150 \mathrm{~V}$ to $180 \mathrm{~V}$ over the scenario, recovering to a mean voltage of 1,000 $\mathrm{V}$ when the LDEW is off. Figure 9(b) shows that the battery current is maintained below the $3000 \mathrm{~A}$ limit for the scenario. The overshoot in the control system design causes a small excess of current to be drawn from the battery, thus increasing the initial voltage drop magnitude.

(a)

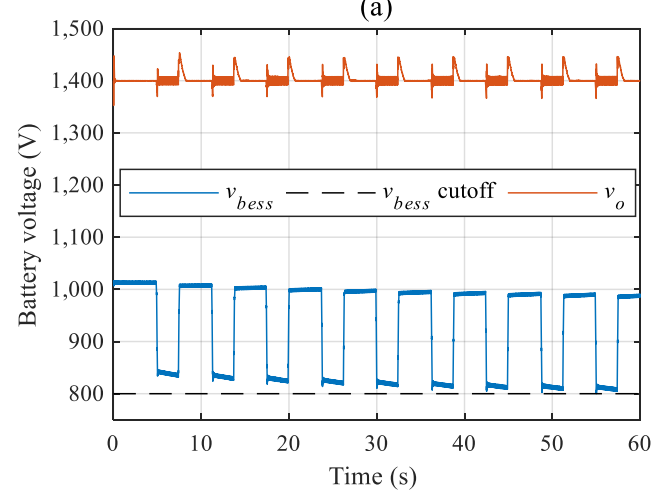

(b)

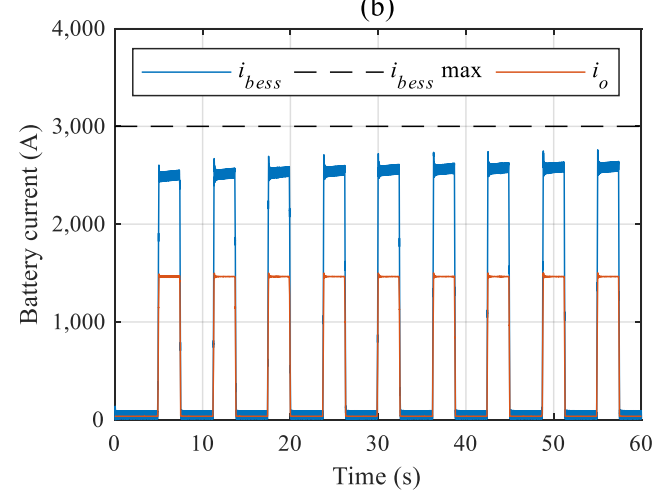

Figure 9: System (a) voltage and (b) current response to 2 MW LDEW load commenced at 70\% SoC

\subsection{Voltage drop with SoC}

The effect of the LDEW load range on the battery voltage drop is demonstrated in Figure 10(a) and (b), intuitively the voltage drop is larger for the larger LDEW load. Comparing Figure 10 (a) and (b) shows that the magnitude of the voltage drop has slightly increased with decreasing SoC. The voltage drop delta between $90 \%$ and $70 \%$ SoC is approximately proportional to the difference in initial voltage, consequently increased current is drawn across the internal resistance of the battery to provide the same load demand.
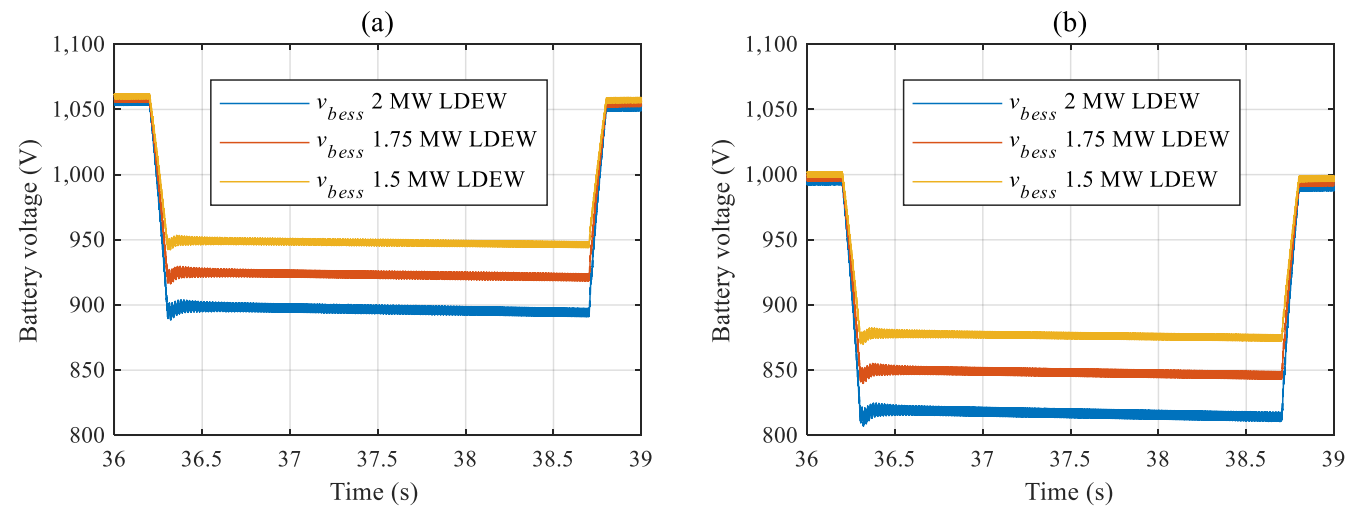

Figure 10: Voltage response to LDEW loading when the simulation commenced at (a) $90 \%$ and (b) $70 \%$ SoC 


\subsection{Operating envelope of the battery powered $\mathrm{LDEW}$}

Through varying the initial SoC of the battery the simulation results indicate that the ESS is capable of facilitating 1.5 MW for the longest engagement time without the need to recharge, completing $>60$ shots for all initial SoC values between $90-50 \%$ as shown in Figure 11 . Contrastingly when the initial SoC is $>80 \%$ the battery is able to provide over $70,1.75 \mathrm{MW}$ shots before recharge, after which the performance reduces linearly to 3 shots when the initial SoC is $50 \%$. For the $2 \mathrm{MW} \mathrm{LDEW} \mathrm{load} \mathrm{the} \mathrm{number} \mathrm{of} \mathrm{shots} \mathrm{reduces} \mathrm{exponentially} \mathrm{to} 0$ at $50 \%$ SoC from 61 shots at $90 \%$ SoC.

It should also be noted that over the course of the engagement there will be a temperature increase in the cells due to pulsing, the temperature rise will decrease the internal resistance of the cells as demonstrated by Jung and Kang (2014) and Wetz et al. (2015). This effect is omitted here due to absence of a thermal model. Therefore, the results in Figure 11 could be considered as a worse case. There are two further options to increase the performance envelope for the 2 MW and 1.75 MW LDEW, firstly, increasing the number of battery strings, or by allowing the diesel generators to contribute a proportion of the LDEW load, this is in the scope of further work. In the latter that stored energy in the ships power system from passive devices, machines and transmission lines would also contribute to the LDEW load.

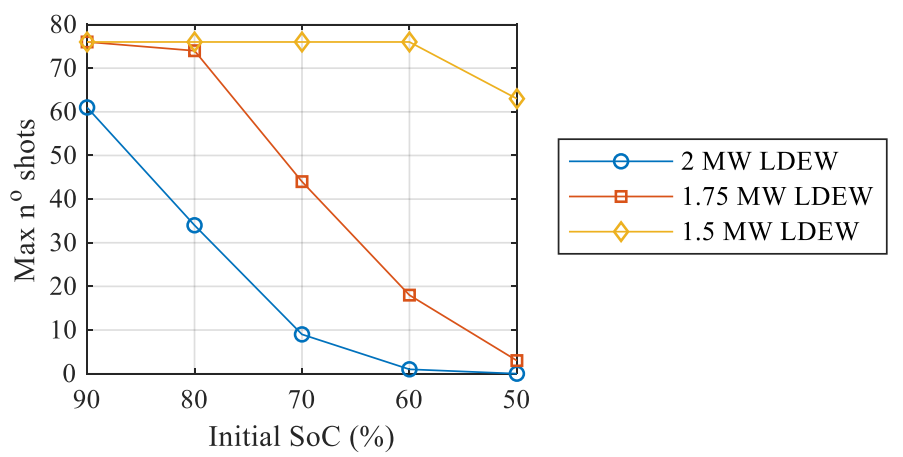

Figure 11: LDEW performance envelope with varying battery SoC

Table 5 provides a summary of the best-case performance of the simulated system when an engagement commences at $90 \%$ SoC. The shot limit is $>60$ consecutive shots ( 8 minutes) for all LDEW powers from $90 \%$ SoC, the results show that for each LDEW power the four minute engagement duration set out by Markle (2018) is surpassed by the four string arrangement at $90 \%$ SoC. However, the subsequent recharge time to $90 \%$ SoC following the engagement is significant at $0.6,0.7$ and 0.82 multiplied by the engagement length for the $1.5,1.75$ and 2 MW LDEW respectively.

Table 5: Summary of battery ESS performance under LDEW loading

\begin{tabular}{llll}
\hline Performance parameter & $\mathbf{1 . 5} \mathbf{M W}$ & $\mathbf{1 . 7 5} \mathbf{M W}$ & $\mathbf{2 ~ M W}$ \\
\hline Maximum number shots from 90\% SoC (480 s limit) & 76 & 76 & 61 \\
Engagement length & $480 \mathrm{~s}$ & $480 \mathrm{~s}$ & $380 \mathrm{~s}$ \\
SoC following engagement & $69.9 \%$ & $67.8 \%$ & $69.2 \%$ \\
Recharge time to 90\% SoC at peak C rate & $302 \mathrm{~s}$ & $333 \mathrm{~s}$ & $312 \mathrm{~s}$ \\
Mean ESS and converter cooling load & $40 \mathrm{~kW}$ & $56 \mathrm{~kW}$ & $59 \mathrm{~kW}$ \\
Peak ESS and converter cooling load & $132 \mathrm{~kW}$ & $172 \mathrm{~kW}$ & $215 \mathrm{~kW}$ \\
\hline
\end{tabular}

The capability to perform a second engagement could be limited by the cooling system, depending on its effectiveness to maintain temperatures within operating limits $20-60^{\circ} \mathrm{C}$ (Hannan et al. 2018), although ideally between $20-25^{\circ} \mathrm{C}$. The model developed in this work assumes an efficient cooling system to maintain ambient temperatures in the ideal range. The calculated cooling load in the model is the summation of the ESS and converter losses, calculated using a polynomial function of the ESS thermal efficiency map in Figure 3, and by measuring the input and output power of the DC/DC converter respectively. The mean losses of the ESS and converter are small relative to the installed generator power $(12 \mathrm{MW})$, the nature of the pulsating load reflects the peak losses, 
which are not insignificant, and this transitory demand highlights the need for further work on integrating the ESS, converter and LDEW with the ships cooling system.

Whilst this study represents a beginning of life assessment of the ESS to meet LDEW demands, the operational stress conditions of repetitive, high current discharge rates could promote cell aging, whereby the cell capacity fades and internal resistance increases as discussed in Huhman et al. (2016). Consequently, aging affects will influence whether the LDEW can operate for four minutes when the ESS is within the SOC ranges established in this work. Further, the auxiliary cooling load will increase due to the change in cell internal resistance. Investigating the degraded performance of the ESS under LDEW operation is the subject of future work.

\section{Conclusions}

This work aimed to establish the ability of a Li-ion NMC battery ESS to act as the power source to anticipated LDEW load demands for a candidate warship with hybrid power and propulsion system. The ESS was integrated with the power system via the main switchboard, the LDEW was collocated on the ESS common bus via a DC/DC boost converter to maximise efficiency and permit isolation from the wider power system during operation. Timedomain simulation results demonstrated that the validated NMC based battery ESS, and control system were able to achieve high rates of fire depending on the initial SoC of the ESS. Cognisant of the stated assumptions, the results of this work have identified operational constraints for future LDEW loads under the battery-based system. These are that the battery should not be less than $80 \%, 70 \%$ and $50 \%$ SoC at the commencement of an engagement for 2, 1.75 and 1.5 MW LDEW loads respectively to ensure maximum shot capability is available.

\section{Acknowledgements}

This paper is in part based on work undertaken by Luke Farrier in part fulfilment of his $\mathrm{PhD}$ in the Marine Research Group at University College London. The authors would like to thank Professor Cat Savage from Defence Equipment and Support for co-supervising and sponsoring this $\mathrm{PhD}$ research. The authors would also like to thank Corvus Energy Ltd for their support in this research.

\section{References}

ABB, 2014. 5SNA 3600E170300 Datasheet [online]. Available from: https://new.abb.com/semiconductors/igbtand-diode-modules [Accessed 25 Apr 2019].

ABB, 2015. 5SLA 3600E170300 Datasheet [online]. Available from: https://new.abb.com/semiconductors/igbtand-diode-modules [Accessed 25 Apr 2019].

Benveniste, G., Rallo, H., Canals Casals, L., Merino, A., and Amante, B., 2018. Comparison of the state of Lithium-Sulphur and lithium-ion batteries applied to electromobility. Journal of Environmental Management, 226 (October 2017), 1-12.

Chemali, E., Preindl, M., Malysz, P., and Emadi, A., 2016. Electrochemical and Electrostatic Energy Storage and Management Systems for Electric Drive Vehicles: State-of-the-Art Review and Future Trends. IEEE Journal of Emerging and Selected Topics in Power Electronics, 4 (3), 1117-1134.

Chen, M. and Mora, G.A.R., 2006. Accurate Electrical Battery Model Capable of Predicting Runtime and I - V Performance. IEEE Transactions on Energy Conversion, 21 (2), 504-511.

Gattozzi, A.L., Herbst, J.D., Hebner, R.E., Blau, J.A., Cohn, K.R., Colson, W.B., Sylvester, J.E., and Woehrman, M.A., 2015. Power system and energy storage models for laser integration on naval platforms. In: 2015 EEE Electric Ship Technologies Symposium (ESTS 2015). Washington DC: IEEE, 173-180.

Gemmell, G., McIntyre, B., and Reilly, M., 2014. Is IFEP a realistic future propulsion system for flexible frigates and destroyers? In: International Naval Engineering Conference. Amsterdam: IMarEST.

Hannan, M.A., Hoque, M.M., Hussain, A., Yusof, Y., and Ker, P.J., 2018. State-of-the-Art and Energy Management System of Lithium-Ion Batteries in Electric Vehicle Applications: Issues and Recommendations. IEEE Access, 6, 19362-19378.

Hannan, M.A., Lipu, M.S.H., Hussain, A., and Mohamed, A., 2017. A review of lithium-ion battery state of charge 
estimation and management system in electric vehicle applications: Challenges and recommendations. Renewable and Sustainable Energy Reviews, 78 (October 2017), 834-854.

Hentunen, A., Lehmuspelto, T., and Suomela, J., 2014. Time-domain parameter extraction method for Theveninequivalent circuit battery models. IEEE Transactions on Energy Conversion, 29 (3), 558-566.

Huhman, B.M., Wetz, D.A., and Mili, L., 2016. Development of a Rep-Rated Pulsed Power System Utilizing Electrochemical Prime Power. IEEE Transactions on Plasma Science, 44 (12), 3398-3408.

IEEE Industry Applications Society, 2018. IEEE 1709 Recommended Practice for $1 \mathrm{kV}$ to $35 \mathrm{kV}$ Medium-Voltage DC Power Systems on Ships.

Jung, S. and Kang, D., 2014. Multi-dimensional modeling of large-scale lithium-ion batteries. Journal of Power Sources, 248, 498-509.

Kalikatzarakis, M., Geertsma, R.D., Boonen, E.J., Visser, K., and Negenborn, R.R., 2018. Ship energy management for hybrid propulsion and power supply with shore charging. Control Engineering Practice, 76 (May), 133-154.

Kazimierczuk, M.K., 2016. Pulse-Width Modulated DC-DC Power Converters. 2nd ed. Pulse-Width Modulated DC-DC Power Converters. John Wiley \& Sons, Ltd.

Langston, J., Steurer, M., Schoder, K., Borraccini, J., Dalessandro, D., Rumney, T., and Fikse, T., 2017. Power hardware-in-The-loop simulation testing of a flywheel energy storage system for shipboard applications. In: 2017 IEEE Electric Ship Technologies Symposium, ESTS 2017. Arlington, VA: IEEE, 305-311.

Markle, S., 2018. Presentation: U.S. Surface Navy Electrical Leap Forward ... .... a Vision for the Future. Naval Postgraduate School: Electric Ships Office, PMS 320.

McNaughtan, N., McKinstry, G., and Wereski, R., 2016. De-risking strategy for the Type 26 Global Combat Ship electrical power and propulsion system. In: International Naval Engineering Conference. Bath: IMarEST.

Mills, K., Xiong, J., Liu, X., and Venkatesh, P., 2018. Informing the power system performance envelope for pulse load operation. In: International Naval Engineering Conference. Glasgow: IMarEST, 1-14.

Nagata, H. and Chikusa, Y., 2016. An all-solid-state lithium-sulfur battery using two solid electrolytes having different functions. Journal of Power Sources, 329, 268-272.

O’Rourke, R., 2015. Navy Shipboard Lasers for Surface, Air, and Missile Defense: Background and Issues for Congress [online]. Available from: https://fas.org/sgp/crs/weapons/R41526.pdf [Accessed 13 Mar 2017].

Özdemir, A. and Erdem, Z., 2018. Double-loop PI controller design of the DC-DC boost converter with a proposed approach for calculation of the controller parameters. Proceedings of the Institution of Mechanical Engineers, Part 1: Journal of Systems and Control Engineering, 232 (2), 137-148.

Radan, D., Southall, M., Benatmane, M., and Butcher, M., 2016. Integration, optimisation and benefits of energy storage for marine applications. In: International Naval Engineering Conference. Bristol: IMarEST.

Southall, M. and Ganti, K., 2018. Battery \& ultra-capacitor based energy storage vessel integration , capabilities , considerations and challenges. In: International Naval Engineering Conference. Glasgow: IMarEST, 342352 .

Wakileh, G.J., 2001. Mitigation of Power System Harmonics. In: Power System Harmonics. Berlin: Springer, 105135.

Wetz, D.A., Shrestha, B., Donahue, S.T., Wong, D.N., Martin, M.J., and Heinzel, J., 2015. Capacity fade of 26650 lithium-ion phosphate batteries considered for use within a pulsed-power system's prime power supply. IEEE Transactions on Plasma Science, 43 (5), 1448-1455. 